\title{
Physiotherapy and the African
}

\author{
BY P. KEEN, Surgeon, Non-European Hospital, Johannesburg.
}

\begin{abstract}
$\mathbf{P}^{\mathrm{H}}$ HYSIOTHERAPY has no place in the African's traditional outlook on the treatment of disease, and physiotherapists have an uphill task in trying to make the "raw" African realise the value of this form of treatment. This may seem a queer statement to make at the beginning of an article aiming to create a better basis of understanding, but after all surgery was in the same situation not many years ago.
\end{abstract}

\section{Influence of Witchdoctors.}

Apart from trauma and a few specific diseases, such as syphilis, tuberculosis, leprosy and, strangely enough, epilepsy, all other illnesses are due to witchcraft or supernatural causes. This is unfortunate as the tribal African will inevitably consult his own "doctor" for most disabilities before seeking the aid of the "white doctor", and consequently cases arrive at the hospital in an advanced stage of the disease. This is particularly disastrous in the field of cancer, and curative treatment is rarely possible. For instance, according to Dr. Burrell in the Transkei the cause of carcinoma of the oesophagus, with the characteristic name of Unhlaza-wombiza or ulcer of the gullet, is said to be caused by a black spider introduced into the victim's beverage by witchcraft.

Surgery has, to a large extent, broken down the barriers though there are still many difficulties to overcome, but the tide has been turned not by precept but by example. A doctor going to a native reserve, however well qualified and experienced, can only hope to gain the confidences of the inhabitants by showing his capabilities, and more important still, his goodwill and sincerity. The only way to convince the raw African is to show him the value of your wares.

\section{Advice to Physiotherapist.}

The Physiotherapist who wishes to treat the African thoroughly and adequately must, apart from more than average skill, have the patience of Job, must be a good judge of human character, must have a sound knowledge of the African's psychological background, should have a grounding of at least one Bantu language, and above all, be inured to disappointments and failures. In fact she must be a superwoman, prepared to compromise and meet the African half-way in his queer but traditional and deeprooted beliefs. And what do we find in our larger hospitals? Like all other departments, the Non-European section of the Physiotherapy Department is the "Cinderella" and is used as a stepping stone to promotion in the main department. Physiotherapists stay for a few months, get fed up and arrange a transfer. There are of course exceptions, and those who have really tried have found the work rewarding and satisfying.

What adequate advice can one give to the physiotherapist working with Africans? I have already given the requirements, a more than average skill, a good judge of human character, the patience of Job, a grounding of at least one Bantu language and a sound knowledge of the African's psychological background. The first three I cannot deal with, you either have them by nature or you must learn to develop them by experience; without them do not attempt to treat the African. It is with the last two attributes I would like to deal very briefly.
A grounding of at least one Bantu language is essential, You do not have to take a complicated course; learn to greet the patient, ask about his welfare and try to give the simpler instructions in Zulu or Sesutu, and even if your clicks are inaccurate you will have gone part of the way to gain the patient's confidence. Get to know his or her little habits, for example when handing the patient his or her card do it with both hands instead of one, a simple gesture, but one that engenders a sympathetic attitude. The original idea of this gesture was to show that there was no weapon in the other hand and it is not necessary to hold the card in both hands, as long as the left hand rests on the right forearm. When I started, I made a list of questions and answers and instructions and had them translated. and within a matter of weeks was able to initiate a conversation and make occasional interjections with good effect. A small booklet of this nature is being prepared by a group of students at the Medical School of the Witwatersrand University and should prove a boon to all physiotherapists working with Africans.

\section{The African's Psychological Background.}

The main object, however, is to deal with the African's psychological background with special reference to physiotherapy, and it must be made clear that these views refer to the raw tribal African and not to his sophisticated urban cousin. Most of the urbanised Africans understand to some extent the value of physiotherapy, but even with them it will be helpful to keep some of the views expressed in mind. Even the most sophisticated African has a subconscious tribal background with all its fears and taboos. Some of our married nurses will bring their children to hospital for treatment, but will at the same time consult their African "doctor". They have already offended their ancestors by becoming nurses and accepting western ideas, and there is always a subconscious fear that the child's illness may in part be due to supernatural causes. I discussed this aspect with one of our nurses and her attitude was "it is better to play for safety", a very natural reaction.

\section{Consultation with a "doctor".}

What happens if a tribal Arican consults his "doctor"? Very often the patient himself does not go, but is represented by several senior members of the family. The patient's troubles are not discussed and no history is taken. An interminable conversation goes on about all sorts of topics, during which the "doctor" chews medicinal herbs, the idea being to placate the ancestors on both sides and encouraging them to co-operate. Suddenly by some outward sign such as going into a trance or belching loudly, the "doctor" announces the cause of the trouble and the line of treatment to be adopted. If witchcraft is involved counter measures are devised, if there are internal troubles, and usually a crab, a snake or a spider is the cause, certain medicaments are prescribed. The pathology is thoroughly discussed and the treatment is thrashed out in great detail-sacrification and inunctions, medicines, enemata and the inhalation of fumes are the commonest forms of treatment.

\section{The Medical Examination.}

In contrast, what do we do with a patient? We take a long history, make prolonged examination (fortunately the stethoscope still has semi-magical properties) and then without much formality give the patient a prescription to take to the dispenser. This is a complete reversal of the 
tribal process. It is essential to explain the source of the pathology, what is happening, and what the treatment is to accomplish. The "rawer" the African the more explanation is required, even if he does not really understand. Physiotherapists could show the patient his X-ray picture, and the trouble should be pointed out, even if it means little to him, and the "why and wherefore" of the treatment should be detailed. If there is a haematoma to be dispersed, tell him it is to chase bad blood away. If an abscess is being treated talk about "bad flesh" and bringing "good blood" to the affected part to make it better-in fact anything to satisfy his mental hunger for explanations.

Some years ago we started group exercises in the wards and $I$ asked some of the older and rawer types what they thought about them. One old man said, "It seems to amuse the lady in white and I am quite happy' to help". Another thought it was part of a religious ceremony to placate his ancestors, and another thought it was just one of the white man's mad ideas, in the same way as he regarded the taking of temperatures with a thermometer. A short explanation of the aims and objects of the various exercises at the time would make all the difference.

\section{Physiotherapy Treatment.}

The raw African would prefer a bottle of nasty medicine or an injection to a course of physiotherapy, however beneficial. I always see to it that my more primitive patient gets a bottle of medicine during his physiotherapy treatment, hoping that he will feel the beneficial effect of the treatment by actual experience. The danger of course, is that he will "blame" the improvement on the bottle of medicine and not the physiotherapy, but it is a risk worth taking.

How can physiotherapists help on these lines? The use of a powder, preferably white, for massage is a good subterfuge particularly if the powder disappears during treatment. The patient will be convinced that the medication has penetrated on the same lines that his own "doctor" uses sacrification and inunctions. One patient complained that the new physiotherapist was not using medicine as her predecessor had done during massage.

One of the most popular treatments is the faradic current. The patient realises that something has penetrated into his system and is making him do something which he cannot do alone.

These observations may appear childish and laughable, but use of them has helped to get a more satisfactory approach to the raw African as far as physiotherapy is concerned.

\section{Anatomical differences between two races.}

Finally it is essential to know something about anatomical and physiological differences in the two races. At first sight this would appear somewhat ridiculous-after all muscles, bones, ligaments and joints are the same whether your skin is white or brown, and why should physiotherapy be different in the two races. To a large extent this is true, but there are certain differences which are worth keeping in mind if the full benefit of the treatment is to be achieved.

\section{GENERAL CONSIDERATIONS.}

There is no doubt in my mind that the raw African's perception of disability is much less marked, and that he has a greater capacity to overcome any disability.

A good example of this was a patient who came to hospital with a trophic ulcer on his little finger which would not heal. It was obvious that he had an ulnar palsy, and on questioning he admitted that he had been stabbed above the elbow three months previously. He had carried on with his work as a garden boy, and was not unduly worried about the ulnar claw hand and anaesthesia. Numerous cases of unreduced dislocation of the shoulder of several years duration have been seen with little apparent disability. After plaster immobilisation for fractures the African's joints re-establish normal function more rapidly, and often physiotherapy is hardly necessary.

\section{Upper Limb.}

In the upper limb there are relative differences in the muscles masses. In the African the muscles which control the arm are about $20 \%$ more powerful than in the European, in the forearm the difference is about $10 \%$, whereas the intrinsic muscles of the hand are on the average $15 \%$ more powerful in the European. These differences are not genetic, but environmental, but nevertheless must be considered. The African's sense of rhythm and music is well known, but Africa has yet to produce a first class violinist, though the banjo with its cruder finger movements has produced many experts. Typing is another accomplishment in which the African finds difficulty in achieving speed.

\section{Lower Limb.}

The lower limb has even more racial differences. The knee joint has been extensively studied and shown several important differences. The African does not tend to extend the knee as much as the European, hyperextension is rare and the locking mechanism not so efficient. The cruciate and collateral ligaments are more powerful in the African and several other minor differences have resulted in the rarity of meniscal lesions in the African. On the other hand, osteoarthritis of the knee is more common and occurs at an earlier age in the African. The interesting para-articular ossification of the medical collateral ligament, the Pellegrini-Stieda syndrome, is very common in the African, and is almost certainly caused by anatomical differences in the medical collateral ligament.

\section{Foot.}

The foot shows some interesting differences. The big toe is shorter in the African and the second toe projects the furthest. The arches of the foot are more elastic and more under muscular control than in the European. The anterior arch flattens much more with weight bearing and there is a distinct widening of the front part of the foot while walking. Weight bearing is also different and the African carries much more weight on the outer side of the foot than the European. It does not require much imagination to visualise the effect of our modern footwear on the next generation of Africans, if the wearing of shoes becomes universal.

\section{The Spine.}

We are still waiting for someone to elucidate differences in the spine. Disc lesions are extremely rare and it is probable that as in the foot and knee the vertebral joints are more under muscular control.

\section{African's Brown Skin.}

What about the African's brown skin? What is the erythema dose for ultraviolet rays? Do infra-red rays penetrate as well through the African's brown skin? What about diathermy? These are all questions still to be answered by some enthusiastic physiotherapist. 
Summary.

For those interested in physiotherapy in the African the following suggestions may help:-

1. Try to acquire a grounding in one or more bantu languages, it need not be profound, but enough to help bridge the gap and create an atmosphere of sincerity.

2. Try to acquire some knowledge of the tribal background of the patients in your area. Though there are common basic beliefs and customs, each area has its own idiosyncrasies and these must be assessed.

3. Give simple explanations of all the procedures used in the Physiotherapy Department and give an outline of the object of the treatment. The more primitive the patient, the more you must talk, and adopt little subterfuges to make the treatment psychologically more effective. If you are interested you will soon find little tricks to help.

This article has been written with the object of helping physiotherapists in this period of transition, at the end of which physiotherapy must find its rightful place in NonEuropean Hospitals. The battle has been half won, but there are still many obstacles to overcome, the main one being the African's reluctance to accept physiotherapy as an essential adjunct to surgery.

What about the future? I can foresee the day when this article will be obsolete, when African physiotherapists will treat their own people. Steps are already being taken to make this dream come true, but in the meantime a better understanding of the African's a:ti ude is essential. The views expressed in this article are personal and may not meet with the approval of all. They are based on a long and varied experience with the African, and if they have given some food for thought, my object will have been attained.

\section{Essay Competition}

Extract from a letter from Dr. P. Keen, Surgeon, NonEuropean, Hospital, Johannesburg.

I do not know if you ever hold competitions in your Journal, but $I$ thought that as a corollary to my article on "Physiotherapy and the African" you might like to hold an essay competition, for which I am prepared to offer a prize of two guineas.

I would like the essays to be invited on the following subject:-

"Why is it that Negroes, while regularly winning gold medals in the sprints and jumping events, have never won an Olympic title in any distance over 800 meters?

Very little has been written on the subject, but I think that there are anatomical and physiological differences which might account for the above statement. I would like to suggest that the competition should be open to Physiotherapists and Physiotherapy students.

Signed: P. KEEN.

\section{a new approach to vasodilatation}

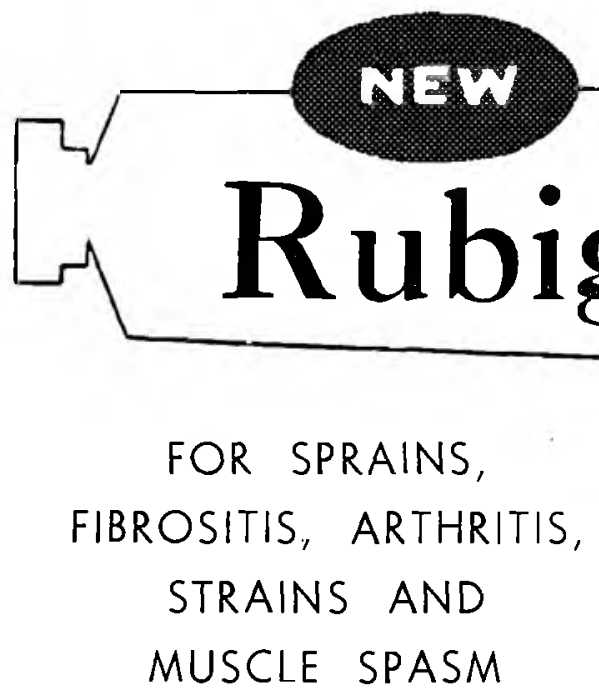

Registered User of Trade Mark and Distributors in South Africa:

WYETH LABORATORIES (PTY.) LTD. 54, STATION STREET, EAST LONDON. by the use of the potent new penetrative

\section{agent}

\section{METHYL NICOTINATE}

in conjunction with the powerful vasodilator, histamine opens the way for the histamine to penetrate tissues rapidly.

There it promotes prolonged, pain-relieving hyperemia, comforting analgesia and soothing warmth.

Formula

Histamine Dihydrochloride

Methyl Nicotinate

Glycol Monosalicylate

Capsicum Oleoresin

These are incorporated in a bland, cosmetically pleasant vehicle.

How Supplied-Tubes of Price-lnexpensive - 5/6 One Ounce. per tube to your patient. 